[Supporting Information (SI) to accompany:]

\title{
One Electron Changes Everything. A Multi-Species Copper Redox Shuttle for Dye-Sensitized Solar Cells
}

W. L. Hoffeditz ${ }^{\mathrm{a}}$, M. J. Katz ${ }^{\mathrm{a}, \mathrm{d}}$, P. Deria ${ }^{\mathrm{a}, \mathrm{e}}$, G. E. Cutsail III ${ }^{\mathrm{a}, \mathrm{f}}$, M. J. Pellin ${ }^{\mathrm{a}, \mathrm{b}}$, O. K. Farha, ${ }^{\text {,a,c }}$, J. T. Hupp*,a,b.

${ }^{a}$ Department of Chemistry, Northwestern University, 2145 Sheridan Road, Evanston, Illinois 60208, United States.

${ }^{b}$ Material Science Division, Argonne National Laboratory, 9700 South Cass Avenue, Argonne, Illinois 60439, United States.

${ }^{c}$ Department of Chemistry, Faculty of Science, King Abdulaziz University, Jeddah, Saudi Arabia

${ }^{d}$ Current address: Department of Chemistry, Memorial University of Newfoundland, St. John's, NL AlB 3X7, Canada.

${ }^{e}$ Current address: Department of Chemistry and Biochemistry, Southern Illinois UniversityCarbondale, 1245 Lincoln Drive, Carbondale, IL 62901, United States.

${ }^{f}$ Current address: Max-Planck Insititut für Chemische Energiekonversion, Stiftstrasse 34 - 36, D-45470 Mülheim an der Ruhr, Germany

\section{Table of Contents}

Section S1. EPR spectral parameters and simulations. $\quad$ S3

Table S1. Copper EPR spectral parameters $\quad$ S3

Figure S1. EPR spectra and simulations for all $\mathrm{Cu}$ species $\quad \mathrm{S} 4$

Figure S2. ENDOR spectra $\quad$ S5

Section S2. UV-Vis spectra for PDTO and TBP ligand titration. $\quad$ S6

Figure S3. UV-Vis spectra of $\mathrm{Cu}(\mathrm{PDTO})^{2+}$ titrated with TBP $\quad$ S6

Figure S4. UV-Vis spectra of $\mathrm{Cu}(\mathrm{TBP})_{\mathrm{x}}(\mathrm{ACN})_{\mathrm{y}}{ }^{+}$titrated with PDTO ligand $\quad \mathrm{S} 7$

Section S3. Dark current/voltage curves and open circuit voltage decay plots for $\mathrm{I}_{3}{ }^{-}$and $\mathrm{Co}(\mathrm{bpy})_{3}{ }^{3+}$. $\quad \mathrm{S} 8$

$\begin{array}{ll}\text { Figure } \mathrm{S}_{5} . \mathrm{I}_{3}^{-} & \mathrm{S} 8\end{array}$

Figure S6. Co(bpy) $3^{3+} \quad$ S9

Section S4. Comparison of J-V curves using high area and standard Pt dark electrodes. $\quad$ S10

Figure S7. Comparison of J-V curves using high area and standard Pt dark electrodes $\quad$ S10 
Section S5. Front-side/back-side IPCE plot and light harvesting.

Figure S8. Front-side/back-side IPCE plot for 0 and $0.5 \mathrm{M}$ added TBP

Figure S9. Light harvesting characteristics of Carbz-PAHTDTT on $\mathrm{TiO}_{2}$

Section S6. J-V curve and $\mathrm{CV}$ with $\mathrm{Cu}(\mathrm{TBP})_{4+\mathrm{x}}(\mathrm{ACN})_{\mathrm{y}}{ }^{2+/+}$.

S13

Figure S10. J-V curve utilizing $\mathrm{Cu}(\mathrm{TBP})_{4+\mathrm{x}}(\mathrm{ACN})_{\mathrm{y}}{ }^{2+/+}$ as a redox couple for DSCs

Figure $\mathrm{S} 11 . \mathrm{CV}$ of $\mathrm{Cu}(\mathrm{TBP})_{4+\mathrm{x}}(\mathrm{ACN})_{\mathrm{y}}{ }^{2+/+}$

S14

Section S7. References 
Section S1. EPR spectral parameters and simulations

Table S1. Copper EPR Spectral Parameters

\begin{tabular}{|l|l|l|l|l|l|l|}
\hline & $g_{\perp}$ & $g_{\|}$ & $A(\mathrm{Cu})_{\perp}{ }^{\mathrm{a}}$ & $A(\mathrm{Cu})_{\|}$ & $A\left({ }^{14} \mathrm{~N}\right)_{\perp}$ & $A\left({ }^{14} \mathrm{~N}\right)_{\|}$ \\
\hline $\mathrm{Cu}\left(\mathrm{CF}_{3} \mathrm{SO}_{3}\right)_{4}{ }^{2+}$ & 2.085 & 2.432 & 35 & 340 & - & - \\
\hline $\mathrm{Cu}(\mathrm{PDTO}$ & 2.0384 & 2.168 & 75 & 512 & 50.5 & 38 \\
& & & & & 38.5 & 38 \\
\hline $\mathrm{Cu}(\mathrm{PDTO})+\mathrm{TBP}^{\mathrm{b}}$ & 2.054 & 2.255 & 47 & 555 & 39 & 30.5 \\
\hline $\mathrm{Cu}(\text { TBP })^{\mathrm{b}}$ & 2.054 & 2.255 & 47 & 555 & 39 & 30.5 \\
\hline $\mathrm{Cu}($ TBP) (powder) & 2.05 & 2.25 & 80 & 560 & - & - \\
\hline
\end{tabular}

${ }^{a}$ All hyperfine values are given in units of $\mathrm{MHz}$

${ }^{\mathrm{b}}$ Simulated with 5 equivalent nitrogens $\left({ }^{14} \mathrm{~N}\right)$ nuclei 


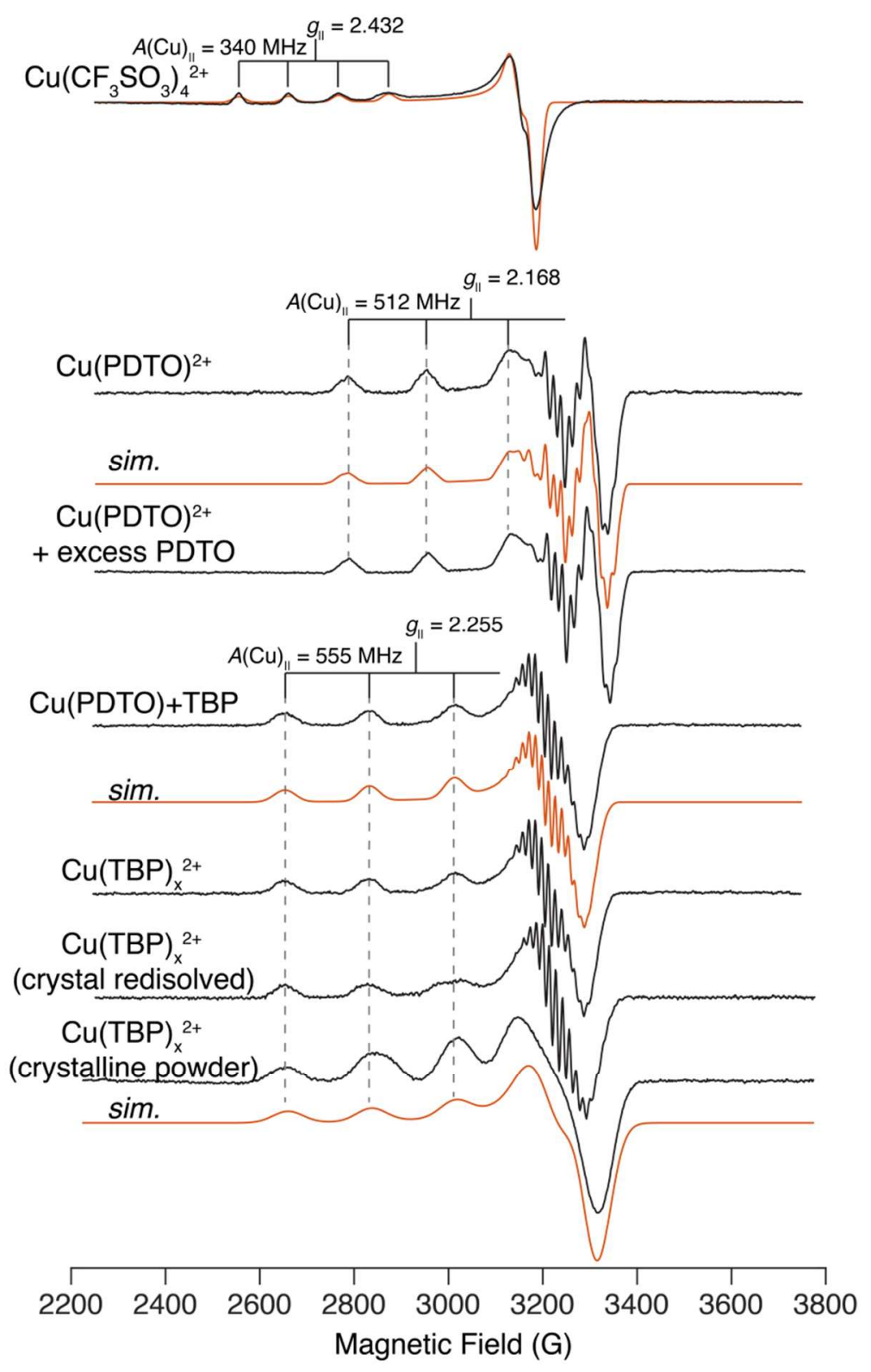

Figure S1. All EPR spectra were collected under conditions described of Figure 5. Simulation parameters are given in Table $\mathrm{S} 1$. 


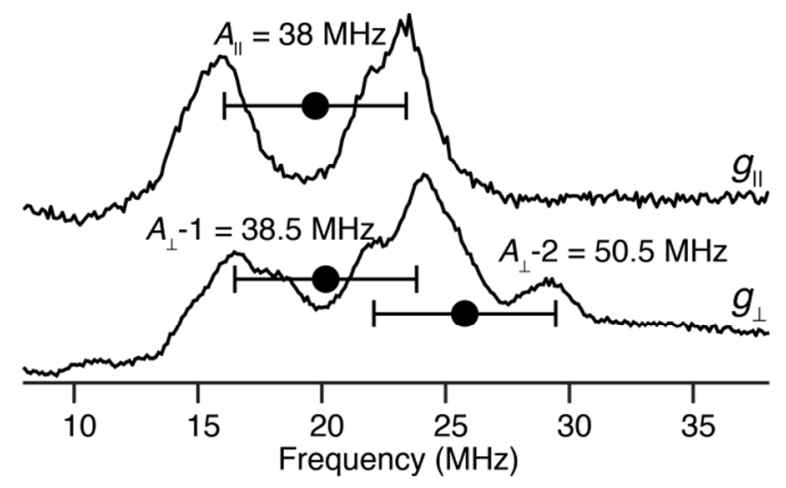

Figure S2. Q-band $(34.93 \mathrm{GHz})$ pulsed Davies ENDOR spectra of $\mathrm{Cu}(\mathrm{PDTO})^{2+}$ at $g_{\|}(11680 \mathrm{G})$ and $g_{\perp}(12140 \mathrm{G})$ taken at $2 \mathrm{~K}$ collected on instrumentation previously described. ${ }^{1}$ The observed ${ }^{14} \mathrm{~N}$ couplings are $A / 2$ centered (circles) split by $2 v_{n}$ (goalposts). At $g_{\|}$, only a single doublet is observed corresponding to overlapping $A_{\|}$for two nitrogens. At $g_{\perp}$, two nitrogens are resolved with couplings of $A\left({ }^{14} \mathrm{~N}-1\right)_{\perp}=38.5$ and $A\left({ }^{14} \mathrm{~N}-2\right)_{\perp}=50.5 \mathrm{MHz}$. These ${ }^{14} \mathrm{~N}$ hyperfine coupling values are employed in the corresponding X-band EPR simulation of $\mathrm{Cu}(\mathrm{PDTO})^{2+}$. Conditions. Pulse sequence: $\pi-\mathrm{T}_{\mathrm{RF}}-\pi / 2-\tau-\pi-\tau-$ echo; $\pi=80 \mathrm{~ns} ; \tau=600 \mathrm{~ns} ; \mathrm{T}_{\mathrm{RF}}=15 \mu \mathrm{s}$; repetition time $=20 \mathrm{~ms}$. 
Section S2. UV-Vis spectra for PDTO and TBP ligand titration.

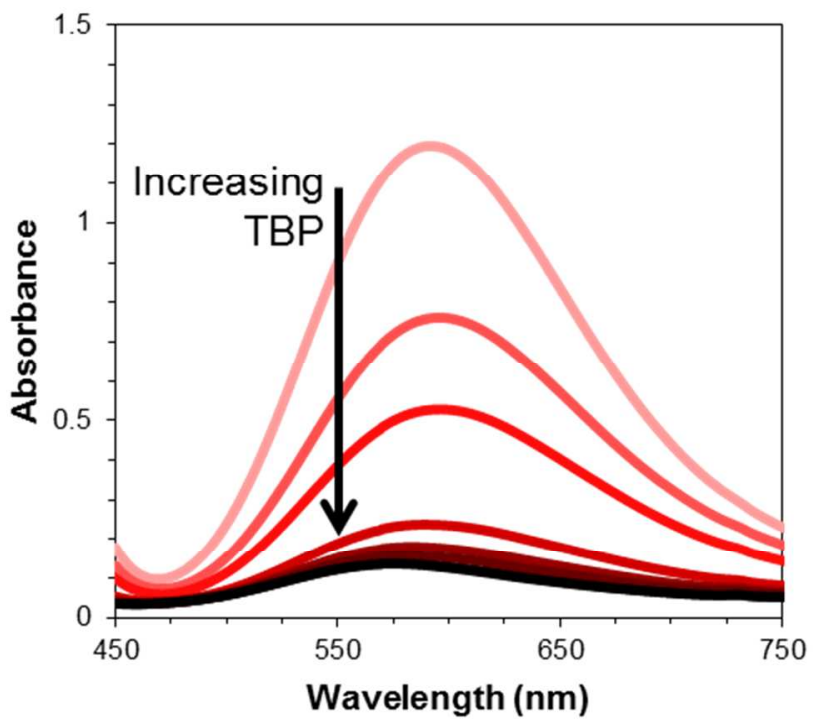

Figure S3. UV-Vis spectroscopy of the $\mathrm{Cu}(\mathrm{PDTO})^{2+}$ complex in acetonitrile titrated with 4-tertbutylpyridine (TBP) corresponding to Figure 5 in the main text. The initial, $\geq 1$ Abs. U. peak contains no TBP. As TBP is added in one equivalent to $\mathrm{Cu}$ amounts, the absorbance magnitude begins to decrease, eventually leveling off around six equivalents. 

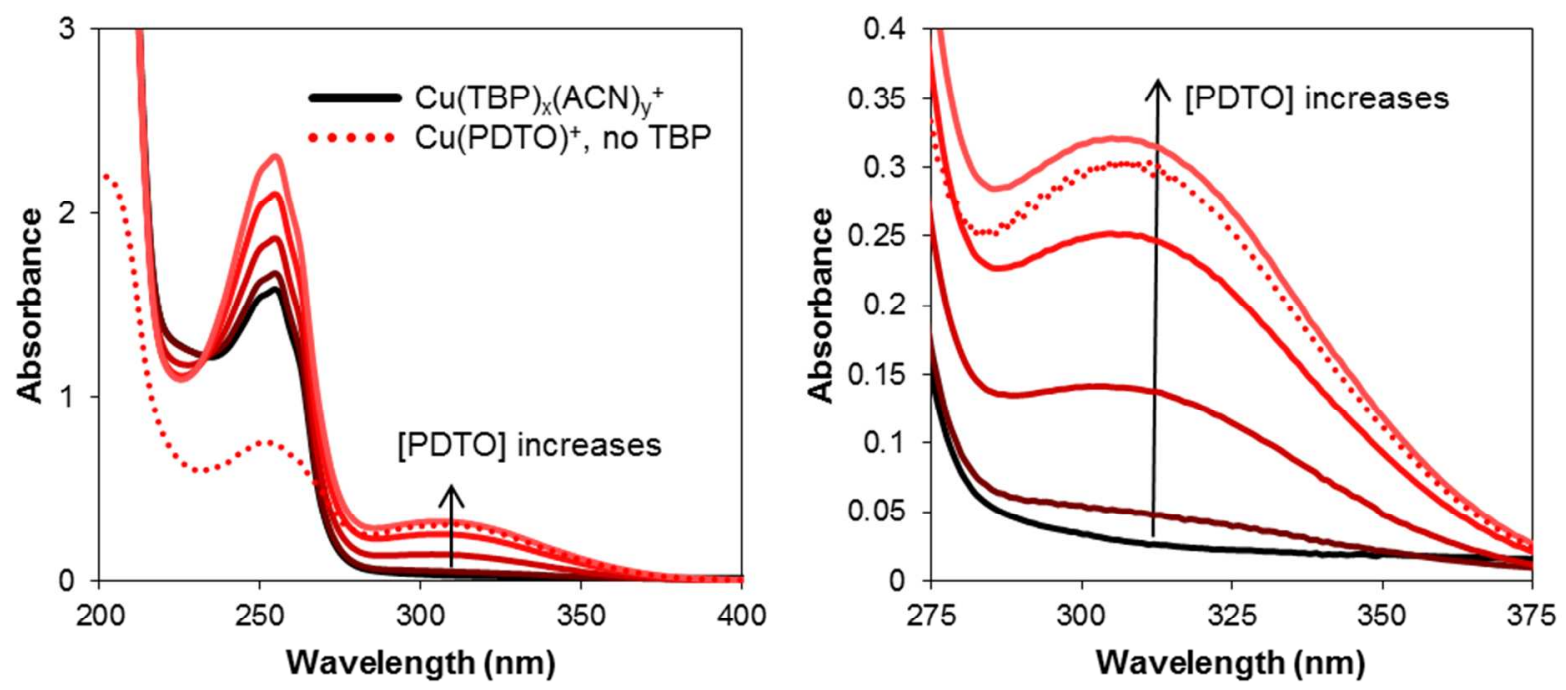

Figure S4. UV-Vis spectra of tetrakisacetonitrile copper(I) hexafluorophosphate in the presence of 10 mole equivalents TBP titrated with PDTO. The figure on the right is a magnified section of the figure on the left. The solid traces begin with no PDTO present (black), then progress to 1:100 PDTO:TBP ratio (1:10 PDTO:Cu ratio), 4:100, 7:100, and finally 1:10 PDTO:TBP (1:1 PDTO:Cu). Of particular importance is the immediate reappearance of the absorption feature associated with sulphur-copper bonds near $315 \mathrm{~nm}$, even when TBP is present in 100X higher concentration. The dotted red line represents $\mathrm{Cu}(\mathrm{ACN})_{4}{ }^{+}$in the presence of one mole equivalent of PDTO and the absence of TBP. The large difference in absorbance at 250 is likely due to the location of a main absorbance feature of TBP in the same area (see Figure 7 in main text). 
Section S3. Dark current/voltage curves and open circuit voltage decay plots for $\mathrm{I}_{3}{ }^{-}$and $\mathrm{Co}(\mathrm{bpy})_{3}{ }^{3+}$.
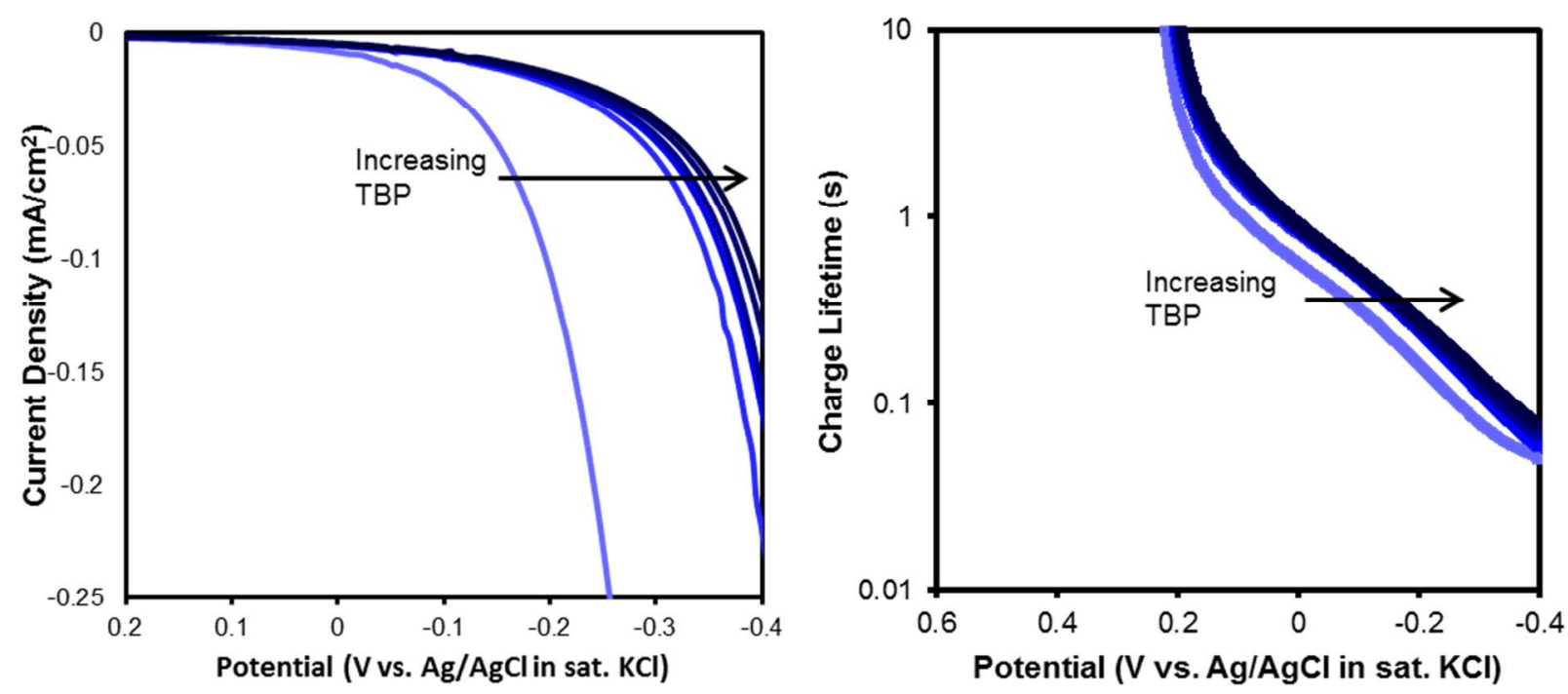

Figure S5. Dark current/voltage curves (left) and open circuit photovoltage decay (OCVD) plots (right) for $0.5 \mathrm{~N} \mathrm{I}_{3}{ }^{-}$in acetonitrile in the presence of increasing amounts of TBP. For the dark current curves, a large, initial increase in onset potential of approximately $200 \mathrm{mV}$ is observed upon the addition of 1 mole equivalent of TBP. Further additions of TBP $(2,3,5,8$, and 10 mole equivalents are shown, with 10 mole equivalents being roughly equal to the standard DSC operating concentration of TBP) have a minimal effect $(\sim 50 \mathrm{mV})$ on dark current onset potential. This effect is likely entirely due to surface association of TBP. OCVD plots give similar results, with the initial addition of TBP causing a small increase in charge lifetime and subsequent additions having a much smaller effect. Again, this effect is likely due to surface association of TBP with $\mathrm{TiO}_{2}$. These effects contrast strongly with those observed with the copper shuttle, supporting the idea of interaction directly between the copper shuttle and TBP. 

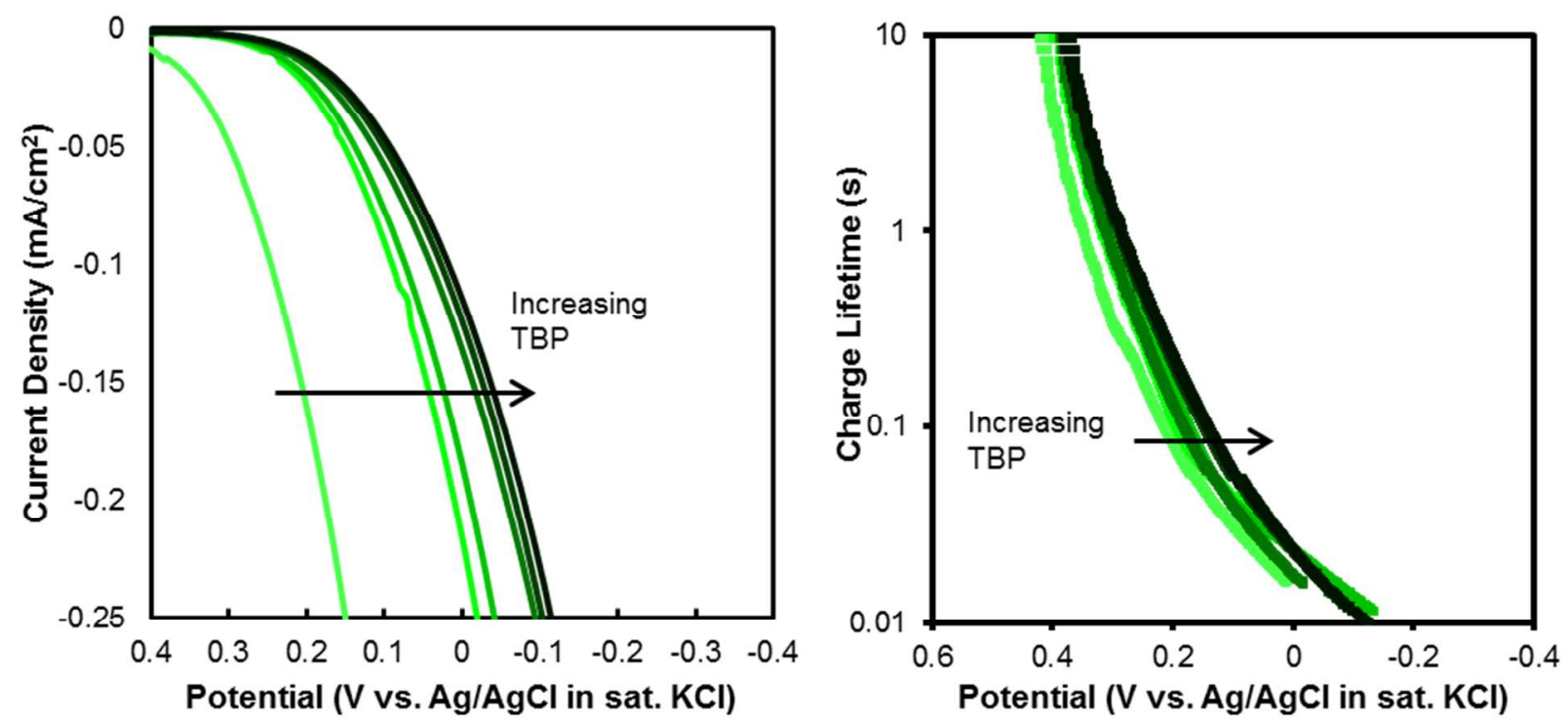

Figure S6. Dark current/voltage curves (left) and open circuit photovoltage decay (OCVD) plots (right) for $0.5 \mathrm{~N} \mathrm{Co}(\mathrm{bpy})_{3}{ }^{3+}$ in acetonitrile in the presence of increasing amounts of TBP. Similar to the trend observed with triiodide, the initial addition of 1 mole equivalent TBP has the largest effect on dark current onset. Subsequent additions to reach 2, 3, 5, 8, and 10 equivalents of TBP again had a significantly smaller effect on dark current onset, likely due to TBP association with $\mathrm{TiO}_{2}$. OCVD plots for $\mathrm{Co}(\mathrm{bpy})_{3}{ }^{3+}$ also show a similar trend as observed with $\mathrm{I}_{3}{ }^{-}$. Together with the data in Figure $\mathrm{S} 1$ for $\mathrm{I}_{3}^{-}$, these results strongly support association of TBP with the copper(II) center as opposed to TBP only associating with $\mathrm{TiO}_{2}$. 
Section S4. Comparison of JV curves using high area and standard Pt dark electrodes.

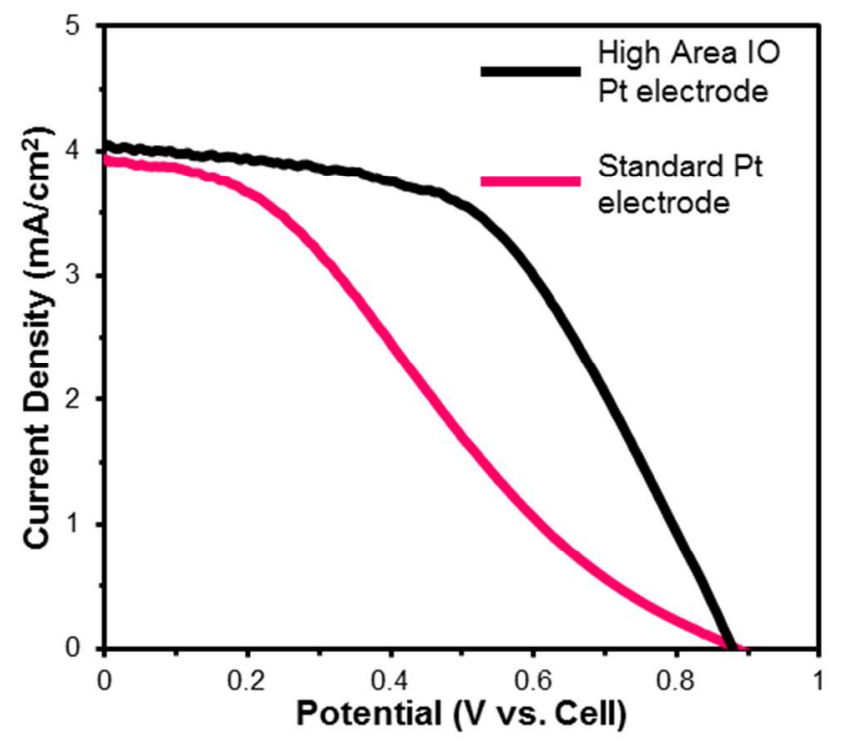

Figure S7. Comparison of JV curves utilizing a standard Pt dark electrode fabricated by the thermal decomposition of $\mathrm{H}_{2} \mathrm{PtCl}_{6}$ (pink) and a high area, $\mathrm{Pt}$ coated inverse opal dark electrode (black). The slow reduction kinetics of the $\mathrm{Cu}(\mathrm{TBP})_{4+\mathrm{x}}(\mathrm{ACN})_{\mathrm{y}}{ }^{2+}$ complex results in a poor fill factor due to charge transfer resistance at the dark electrode. The high area of a Pt coated inverse opal film remedies this problem by increasing the rate of the reaction via increasing the number of reactive sites, explained in detail in a previous publication. ${ }^{2}$ 
Section S5. Front-side/back-side IPCE plot.

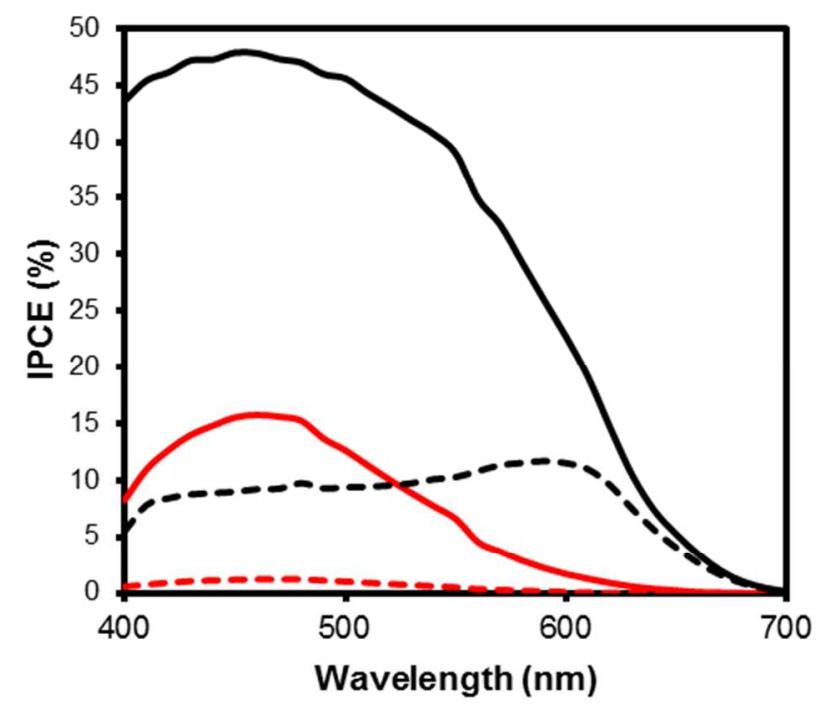

Figure S8. Front-side (solid lines) and back-side (dashed lines) incident photon-to-electron conversion efficiency (IPCE) for devices with no added 4-tert-butylpyridine (TBP, red traces) and $0.5 \mathrm{M}$ added TBP (black traces). At an illumination wavelength of $500 \mathrm{~nm}$ the photoelectrode features an absorbance of $c a .3$ (see Figure S9 below). The photocurrent due to back-side illumination at this wavelength is only about $20 \%$ of the value obtained with front-side illumination. Thus, the first $80 \%$ of absorbed photons appear to be generated to distant from the current collector to contribute to $\mathrm{J}_{\mathrm{sc}}$. Assuming uniform loading of dye on the photoelectrode, $80 \%$ of the incident photons at $500 \mathrm{~nm}$ will be absorbed within the first 1.9 microns of the electrode. For back-side illumination, therefore, electrons generated at any distance beyond 1.9 microns are likely to be collected by the conductive glass material sited at the opposite side of the $\sim 8$-micron-thick $\mathrm{TiO}_{2}$ electrode. 

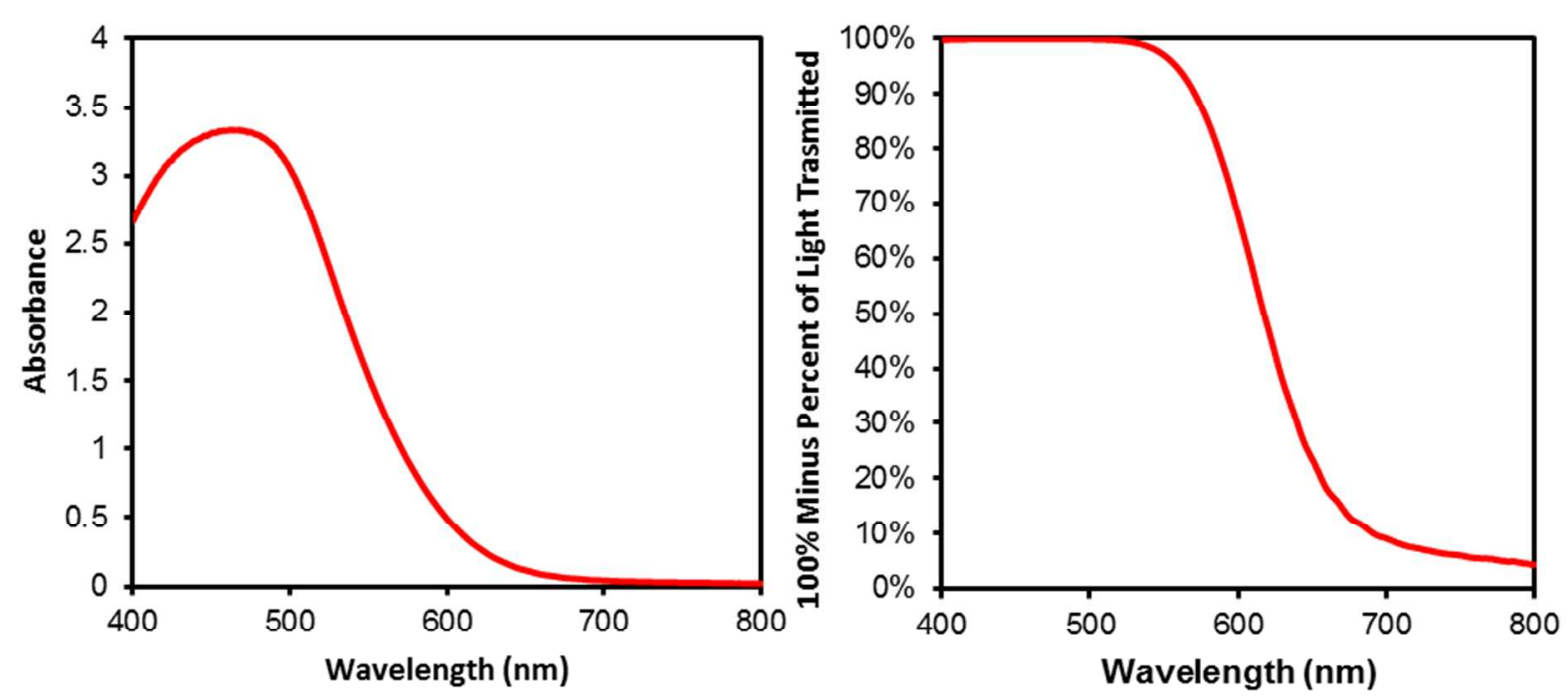

Figure S9. Light harvesting characteristics of Carbz-PAHTDTT dye on $\sim 8$ micrometer thick $\mathrm{TiO}_{2}$ films plotted as absorbance vs. wavelength (left) and as a percentage of light absorbed (right). 
Section S6. J-V curve and $\mathrm{CV}$ with $\mathrm{Cu}(\mathrm{TBP})_{4+\mathrm{x}}(\mathrm{ACN})_{\mathrm{y}}{ }^{2+/+}$.

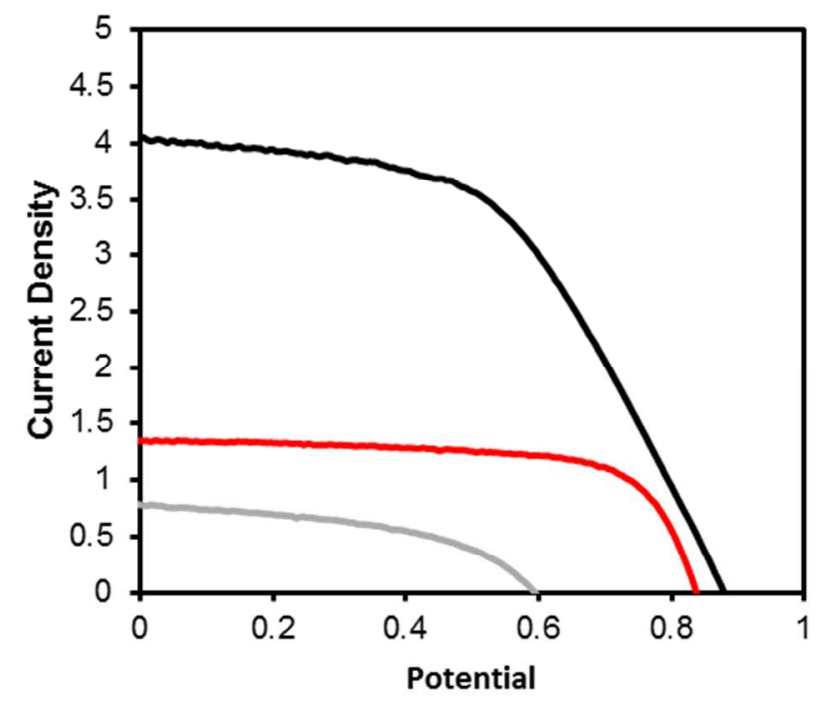

Figure S10. J-V curve of $\mathrm{Cu}(\mathrm{TBP})_{4+\mathrm{x}}(\mathrm{ACN})_{\mathrm{y}}{ }^{2+/}$ (gray line) utilized as a redox shuttle in a DSC. PDTO is not present in solution in this device. For comparison, the J-V curves obtained from the $\mathrm{Cu}(\mathrm{PDTO})^{2+/+}$ shuttle (red line) and the mixed system $\mathrm{Cu}(\mathrm{TBP})_{4+\mathrm{x}}(\mathrm{ACN})_{\mathrm{y}}{ }^{2+} / \mathrm{Cu}(\mathrm{PDTO})^{+}$shuttle (black line) are also shown. 


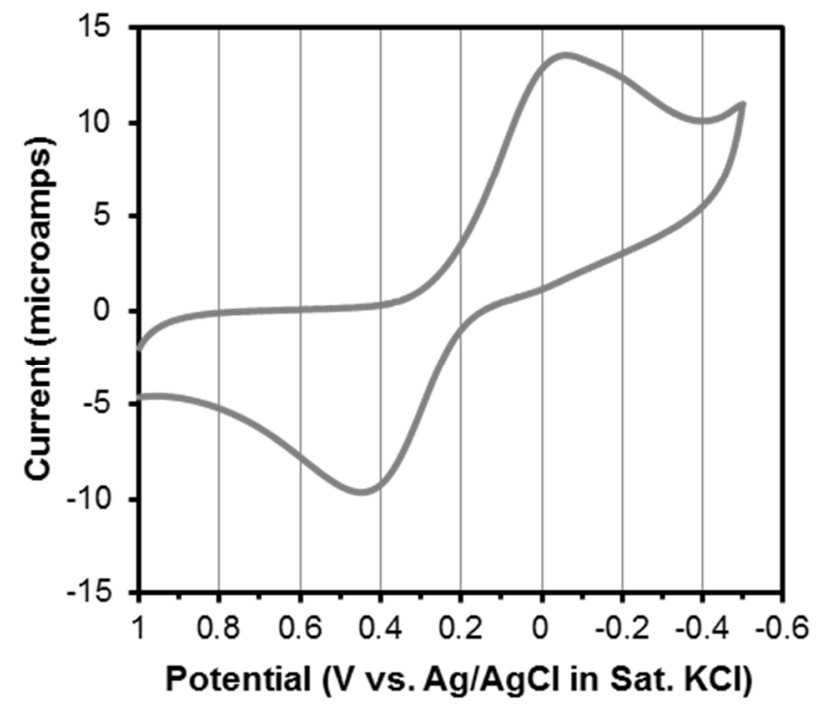

Figure S11. Cyclic voltammagram of $\mathrm{Cu}(\mathrm{TBP})_{4+\mathrm{x}}(\mathrm{ACN})_{\mathrm{y}}{ }^{2+/+}$. 


\section{Section S7. References}

(1) Davoust, C. E.; Doan, P. E.; Hoffman, B. M. Q-Band Pulsed Electron Spin-Echo Spectrometer and Its Application to Endor and Eseem. Journal of Magnetic Resonance, Series A 1996, 119, 38-44.

(2) Hoffeditz, W. L.; Katz, M. J.; Deria, P.; Martinson, A. B. F.; Pellin, M. J.; Farha, O. K.; Hupp, J. T. High-Surface-Area Architectures for Improved Charge Transfer Kinetics at the Dark Electrode in Dye-Sensitized Solar Cells. ACS Appl. Mater. Interfaces 2014, $6,8646-8650$. 